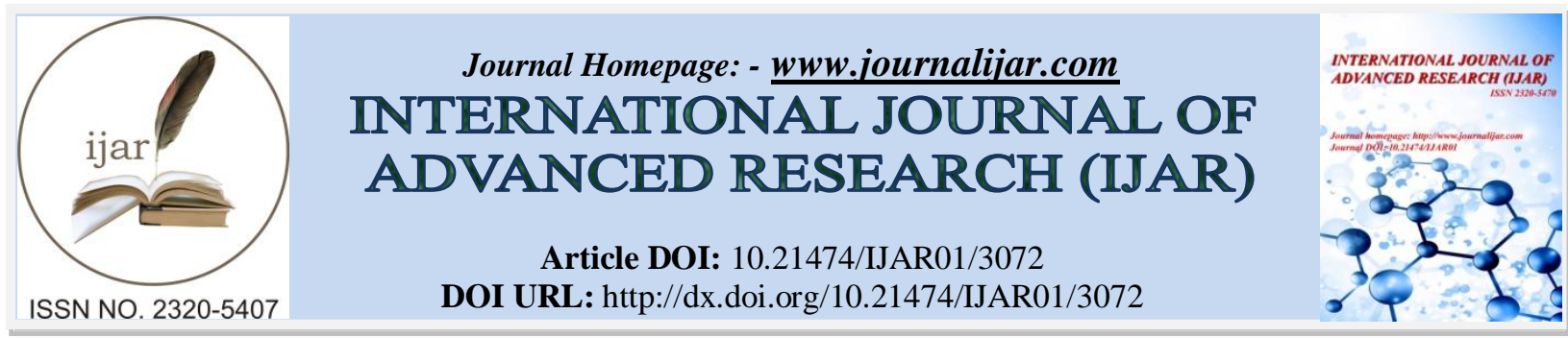

RESEARCH ARTICLE

\title{
EVALUATION OF KNOWLEDGE ABOUT THE DANGEROUS EFFECT OF EXCESSIVE USE OF ANTIBIOTICS IN ASIR CITY.
}

\section{Alhanoof Alshaghrood, Razan Alhumayed, Fatimah Alsiary, Rahaf Alhayafah, Asma Ogran, Mastoor} Alshahrani and Sarah Assiri.

\section{Manuscript Info}

Manuscript History

Received: 03 December 2016

Final Accepted: 30 December 2016

Published: January 2017

\section{Abstract}

Antibiotics excessive and abusive use is associated with increased resistance and complications that have been well recognized worldwide in the literature.

Objective: The aim of this study was to assess knowledge, behavior and attitude toward antibiotics use among residents of 'Asir region.

Method: Our study was carried out among a sample of 409 residents in Asir region. To reach our goal and in order to collect the necessary informations, consenting residents responded to a questionnaire and the descriptive approach was employed in data and facts collection, classification and tabulation.

Results: The sample is consisted of $65,8 \%$ women and $34,2 \%$ men. The sample of individuals was distributedaccording to age, gender and educational level.Our study showed that(46.7\%)of sample individuals are taking antibiotics without doctor's advice. Among the respondents, $(38,4 \%)$ do not usually complete the course of antibiotics, however, $(69,9 \%)$ of sample individuals do believe that the bacterial resistance to antibiotics appears in a case of an uncompleted antibiotic course. The majority of respondents $(59.4 \%)$ of sample individuals are often taking the antibiotics by doctor, yet,(10.5\%) of sample individuals are taking the antibiotics often by themselves and $(9.3 \%)$ of sample individuals said that common cold drives them to buy and take antibiotics. The majority of sample individuals $(35.5 \%)$ believe that the period in which they define treatment failure in their opinion is ranging from one day to three days; also, $(35.7 \%)$ of respondents do not know what are the risks and complications of antibiotics and (76.5\%) review their doctor in the case of treatment failure.

Copy Right, IJAR, 2016,. All rights reserved.

Future interventional directions to improve knowledge about antibiotic use among residents of Asir are necessary. To achieve this, fundamental keystones for controlling antibiotics misuse and subsequent antibiotic resistance should be taken. 


\section{Methodological procedures of the empirical study:- Introduction:-}

The goal of the current research is to measure the extent of the awareness and knowledge of the community towards the use of antibiotics and its risks in 'Asir region; this chapter deals with the description of empirical research procedures carried out by the researcher to achieve the research objectives, including determining the research approach, the research community, research sample, and presentation of the study findings.

\section{Research Methodology:-}

In order to achieve the objectives of the study; the researcher will use the descriptive analytical approach:" The descriptive approach is specified in data and facts collection, classification and tabulation. Besides, analyzing the results adequately and in-depth. It also includes some kind of explanation for these results. That is the reason behind using of measurement, classification, and interpretation methods. In order to extract significant exclusions then get generalizations about the phenomenon included in the study.

\section{Community and sample of research:-}

The current community of research includes all the residents in Asir region, as the research sample included (409) individual of them.

Research tool:

Having reviewed the educational literature, and the previous studies concerning the research subject, the researcher built and developed a questionnaire to measure the extent of the awareness and knowledge of the community towards the use of antibiotics and its risks in the region of Asir, Saudi Arabia. In order to obtain the necessary information from the sample items to answer the research questions, the researcher relied on the questionnaire as an essential tool to collect the required data in support of the theoretical aspect of applied research to answer her questions and to achieve her goals.

The researcher has designed the questionnaire by searching the theoretical literature research and reviewing the previous studies, as well as access to some tools and measurements of other studies that are related to the current research subject. The questionnaire has included a series of questions that supports the subject of research through its direct relation to research objectives and its questions. The questionnaire has been prepared to achieve these goals. Also, it has been applied to the individuals in the research sample, and the results were as follows:

\section{Presentation and discussion of the results of the first question relating to age}

The frequencies and percentages of the sample individuals were calculated according to age.

1. The distribution of sample individuals according to age:-

Table 1:- Sample individuals' distribution according to age

\begin{tabular}{|l|l|l|l|}
\hline No. & Age & Frequency & Percent \\
\hline 1 & Less than 20 years & 7 & $1.7 \%$ \\
\hline 2 & From 20 to less than 30 years old & 125 & $30.6 \%$ \\
\hline 3 & From 30 to less than 40 years old & 118 & $28.9 \%$ \\
\hline 4 & From 40 to less than 50 years old & 116 & $28.4 \%$ \\
\hline 5 & 50 years and more & 43 & $10.5 \%$ \\
\hline Total & 409 & $100.0 \%$ \\
\hline
\end{tabular}

As it is shown in (Table 1) that a percentage of (1.7\%) of sample individuals are of age less than 20, while there are a percentage of $(30.6 \%)$ of individuals aged between 20 to less than 30 years old, a percentage of $(28.9 \%)$ of sample individuals aged between 30 and less than 40 years old, and the percentage of $(28.4 \%)$ of individuals aged 40 and less than 50 years old. Also, a percentage of (10.5\%) of sample individuals have aged more than 50 years and more. These results were attributed to the increase in the number of youth with ages between 20 years and less than 30 years in Asir region. 
Figure 1:- Shows sample individuals' distribution according to age

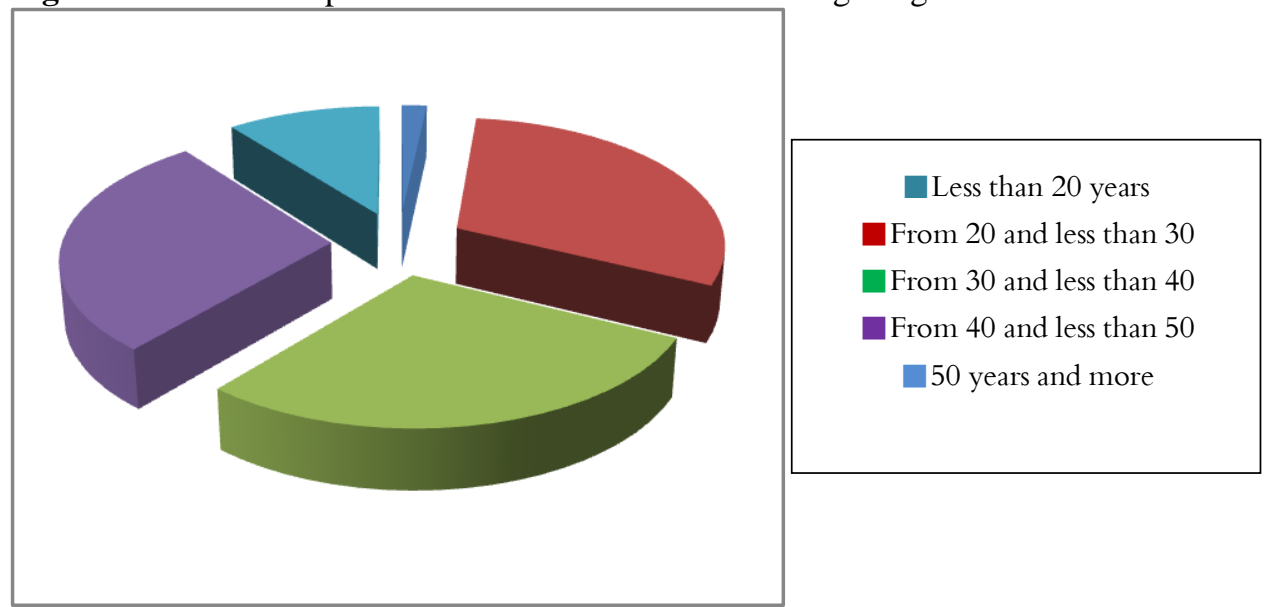

Presentation and discussion of the results of the second question relating to sex

The frequencies and percentages of the sample individuals were calculated according to sex.

2. The distribution of sample individuals according to sex:

Table 2:- Sample individuals' distribution according to sex

\begin{tabular}{|l|l|l|l|}
\hline No. & Sex & Frequency & Percent \\
\hline 1 & Male & 140 & $34.2 \%$ \\
\hline 2 & Female & 269 & $65.8 \%$ \\
\hline Total & 409 & $100.0 \%$ \\
\hline
\end{tabular}

As it is shown in (Table 2) that there is a percent of (34.2\%) from the sample individuals are of males, and a percentage of $(65.8 \%)$ from the sample individuals are of females. These results were attributed to the increase in the number of females more than males in Asir region.

Chart 2:- shows Sample individuals' distribution according to sex

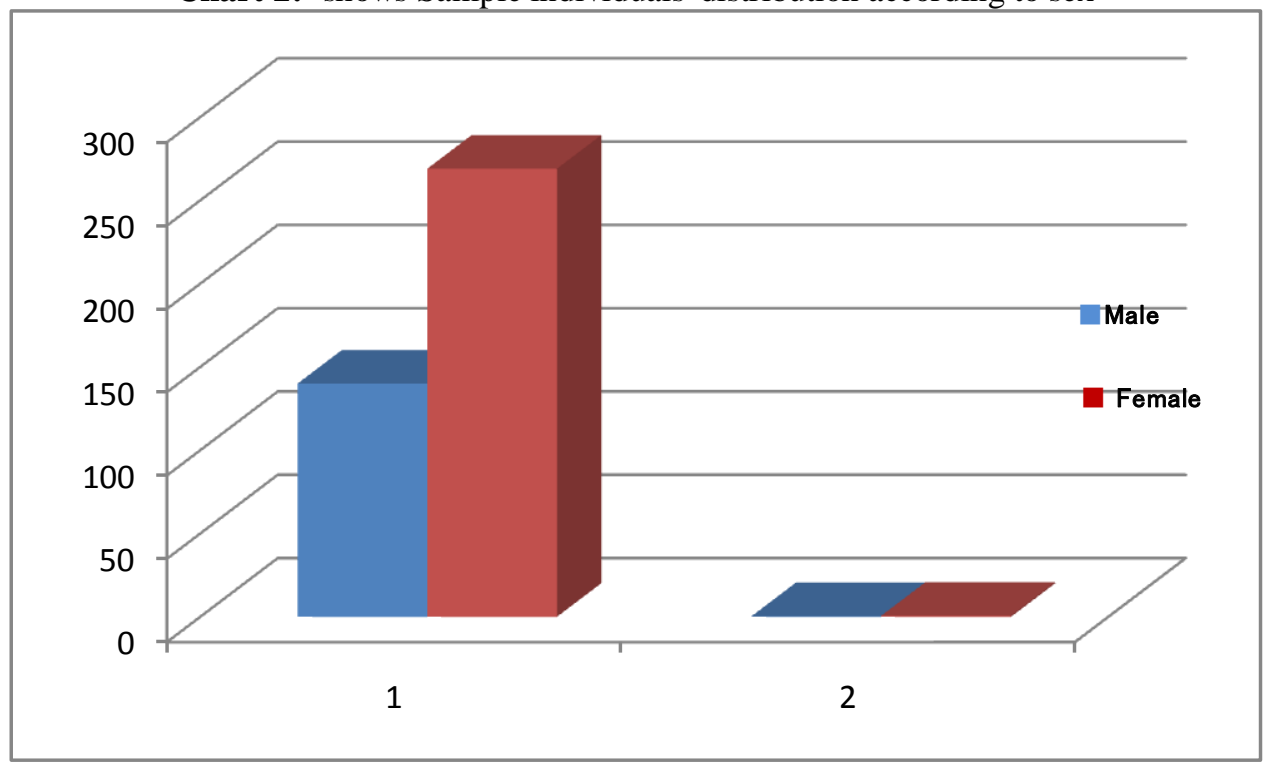

Presentation and discussion of the results of the third question regarding the educational level

The frequencies and percentages of the sample individuals were calculated according to the educational level.

3. The distribution of sample individuals according to the educational level: 
Table 3:- Sample individuals' distribution according to the educational level

\begin{tabular}{|l|l|l|l|}
\hline No. & The educational Level & Frequency & Percent \\
\hline $\mathbf{1}$ & Primary & 8 & $2.0 \%$ \\
\hline $\mathbf{2}$ & Average & 9 & $2.2 \%$ \\
\hline $\mathbf{3}$ & Secondary Academic & 70 & $17.1 \%$ \\
\hline $\mathbf{4}$ & & 322 & $78.7 \%$ \\
\hline & Total & 409 & $100.0 \%$ \\
\hline
\end{tabular}

As it is shown in table No.3 that a percentage of $(2.0 \%)$ of sample individuals hold a primary qualification, while there are a percentage of $(2.2 \%)$ of individuals hold an average qualification, a percentage of $(17.1 \%)$ of sample individuals has a secondary qualification, and the percentage of (78.7\%) of individuals hold a university degree. These results were attributed to the people of Asir who care about the educational process and keen to pursue their academic career and keep acquiring the highest degrees of knowledge.

Figure 3:- Shows Sample individuals' distribution according to the educational level

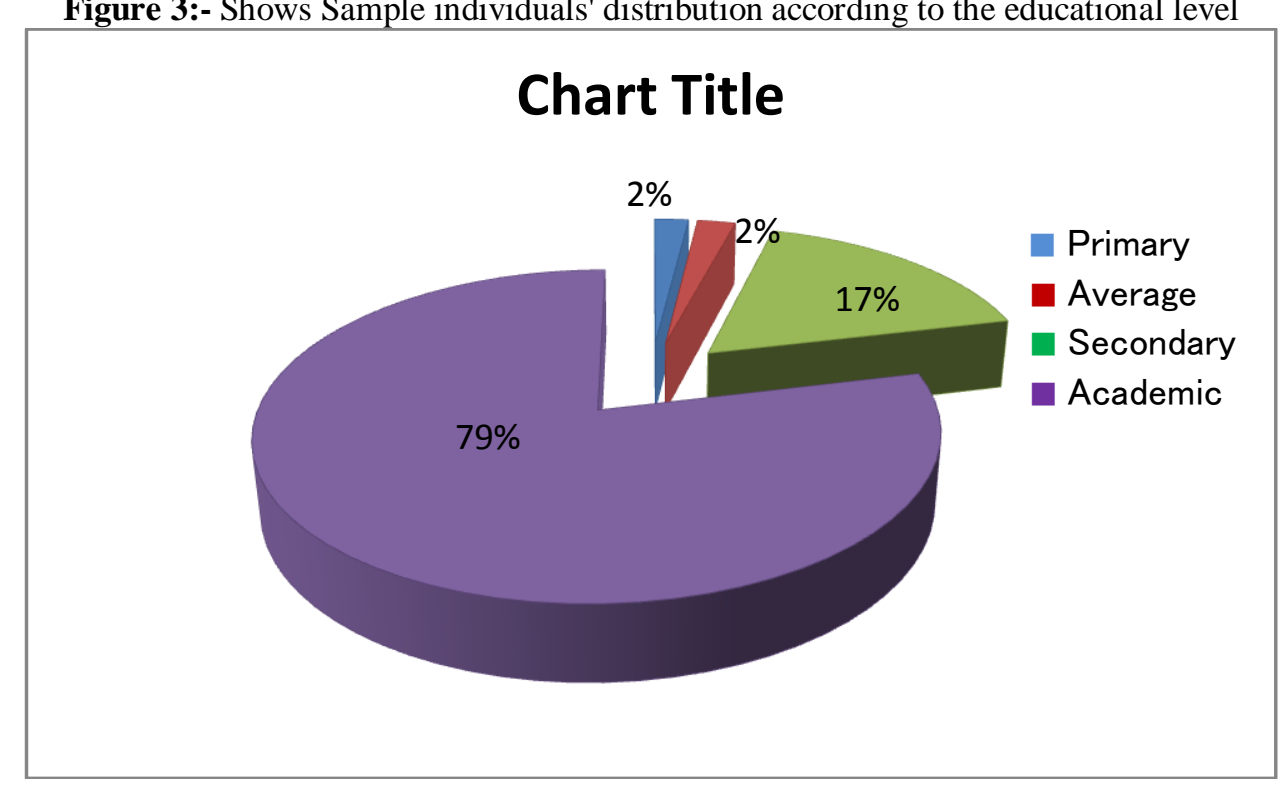

Presentation and discussion of the results of the fourth question "Are you taking Antibiotics without Doctor's advice?"

The frequencies and percentages of the sample individuals were calculated according to the answer of "Are you taking Antibiotics without Doctor's advice?" question.

4. The distribution of sample individuals according to the answer of "Are you taking Antibiotics without Doctor's advice?" question:

Table 4:- Sample individuals' distribution according to the answer of "Are you taking Antibiotics without Doctor's advice?" question

\begin{tabular}{|l|l|l|l|}
\hline No. & Are you taking Antibiotics without Doctor's advice? & Frequency & Percent \\
\hline $\mathbf{1}$ & No & 218 & $53.3 \%$ \\
\hline $\mathbf{2}$ & Yes & 191 & $46.7 \%$ \\
\hline & Total & 409 & $100.0 \%$ \\
\hline
\end{tabular}

As it is shown in table No.4 that a percentage of $(53.3 \%)$ of sample individuals do not take antibiotics without doctor's advice, while there is a percentage of (46.7\%) of sample individuals are taking antibiotics without doctor's advice. These results were attributed to the interest of the majority of individuals included in the sample to follow doctor's instructions,considering doctor as the worthier person to trust regarding taking drugs generally and antibiotics in particular. 
Chart 4:- Shows Sample individuals' distribution according to the answer of "Are you taking Antibiotics without Doctor's advice?" question

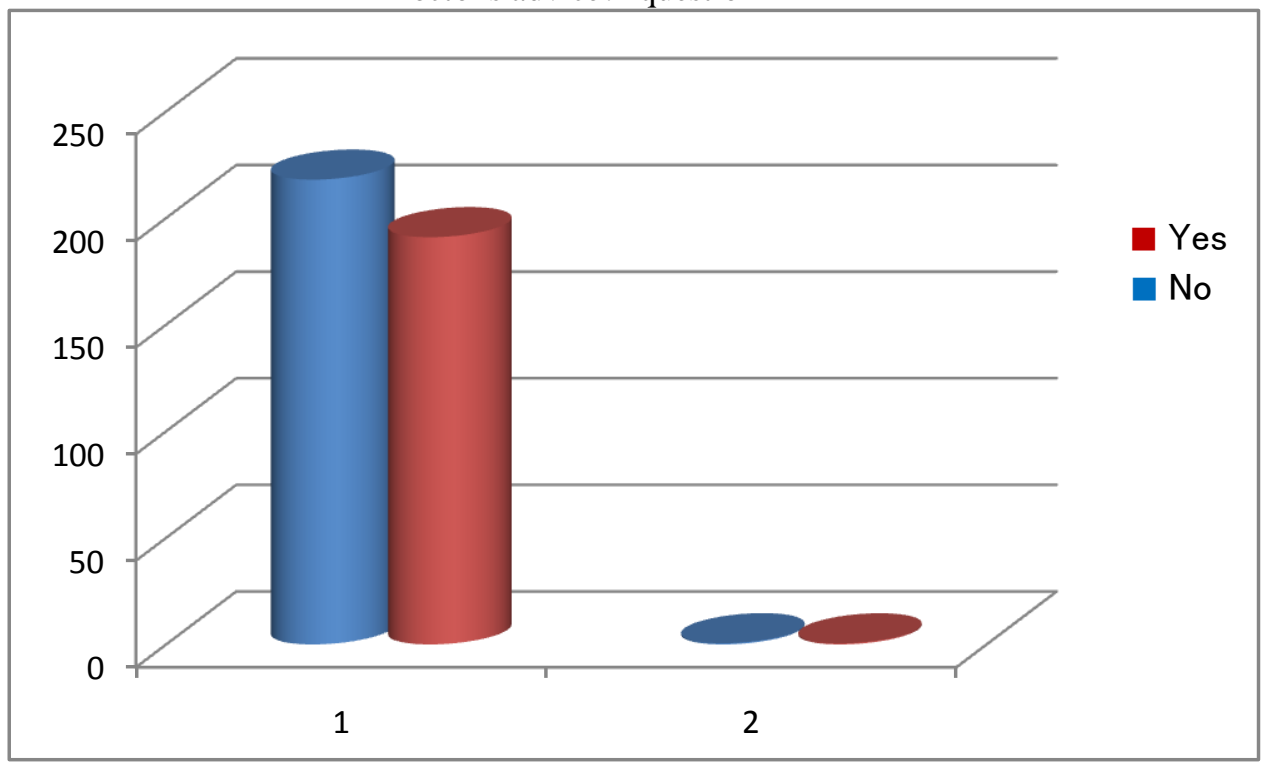

Presentation and discussion of the results of the fifth question on "Whether the high temperature or so called fever is a strong indication to use antibiotics"

The frequencies and percentages of the sample individuals were calculated according to the answer of "Whether the high temperature or so called fever is a strong indication to use antibiotics" question.

5. The distribution of sample individuals according to the answer of "Whether the high temperature or so called fever is a strong indication to use antibiotics" question:

Table 5:- Sample individuals' distribution according to the answer of "Whether the high temperature or so called fever is a strong indication to use antibiotics" question.

\begin{tabular}{|l|l|l|l|}
\hline No. & $\begin{array}{l}\text { Whether the high temperature or so called fever is a strong indication to } \\
\text { use antibiotics }\end{array}$ & Frequency & Percent \\
\hline 1 & No & 261 & $63.8 \%$ \\
\hline 2 & Yes & 148 & $36.2 \%$ \\
\hline & Total & 409 & $100.0 \%$ \\
\hline
\end{tabular}

As it is shown in table No.5 that a percentage of $(63.8 \%)$ of sample individuals do not consider having a high temperature or fever is not a strong indication to use antibiotics, while there are a percentage of $(36.2 \%)$ of sample individuals consider having a high temperature or fever as a strong indication to use antibiotics. These results were attributed to the sample individuals' knowledge about the causes of high temperature which are numerous, variable, and don't require having antibiotics as a treatment. It may have another specific treatment. Also, they believe they need to take doctor's advice before using antibiotics. 
Chart 5:- shows Sample individuals' distribution according to the answer of "Whether the high temperature or so called fever is a strong indication to use antibiotics" question

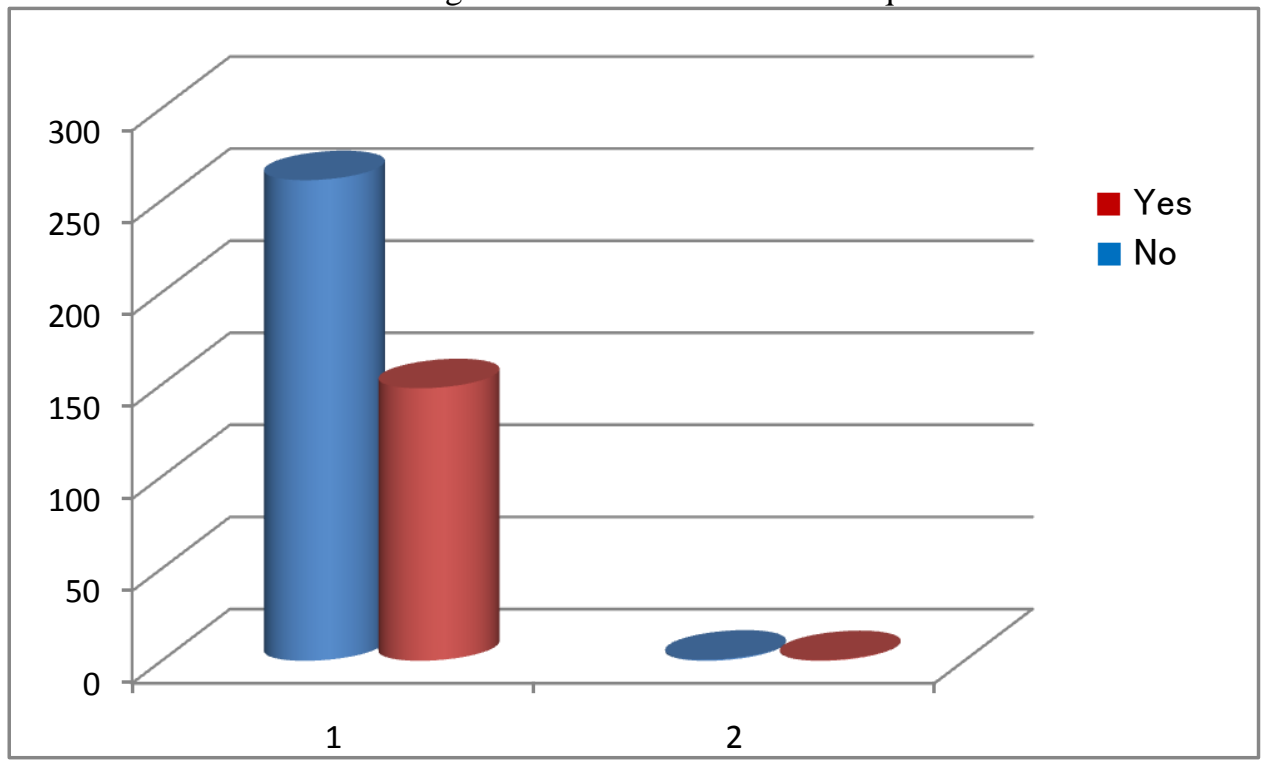

Presentation and discussion of the results of the sixth question on "Do you usually complete the course (the period specified for use by a physician) of antibiotics?"

The frequencies and percentages of the sample individuals were calculated according to the answer of "Do you usually complete the course (the period specified for use by a physician) of antibiotics?"question.

6. The distribution of sample individuals according to the answer of "Do you usually complete the course (the period specified for use by a physician) of antibiotics?"question:

Table 6:- Sample individuals' distribution according to the answer of "Do you usually complete the course (the period specified for use by a physician) of antibiotics?" question

\begin{tabular}{|l|l|l|l|}
\hline No. & $\begin{array}{l}\text { "Do you usually complete the course (the period specified for use by a } \\
\text { physician) of antibiotics?" }\end{array}$ & Frequency & Percent \\
\hline 1 & No & 157 & $38.4 \%$ \\
\hline 2 & Yes & 252 & $61.6 \%$ \\
\hline & Total & 409 & $100.0 \%$ \\
\hline
\end{tabular}

As it is shown in table No.6 that a percentage of (38.4\%) of sample individuals do not usually complete the course (the period specified for use by a physician) of antibiotics, while there are a percentage of $(61.6 \%)$ of sample individuals usually complete the course (the period specified for use by a physician) of antibiotics. These results were attributed to the majority of sample individuals' conviction about the importance of doctor's opinion. As they work on the implementation of the doctor's directions properly in order to eliminate the disease. 
Chart 6:- shows Sample individuals' distribution according to the answer of "Do you usually complete the course (the period specified for use by a physician) of antibiotics?" question

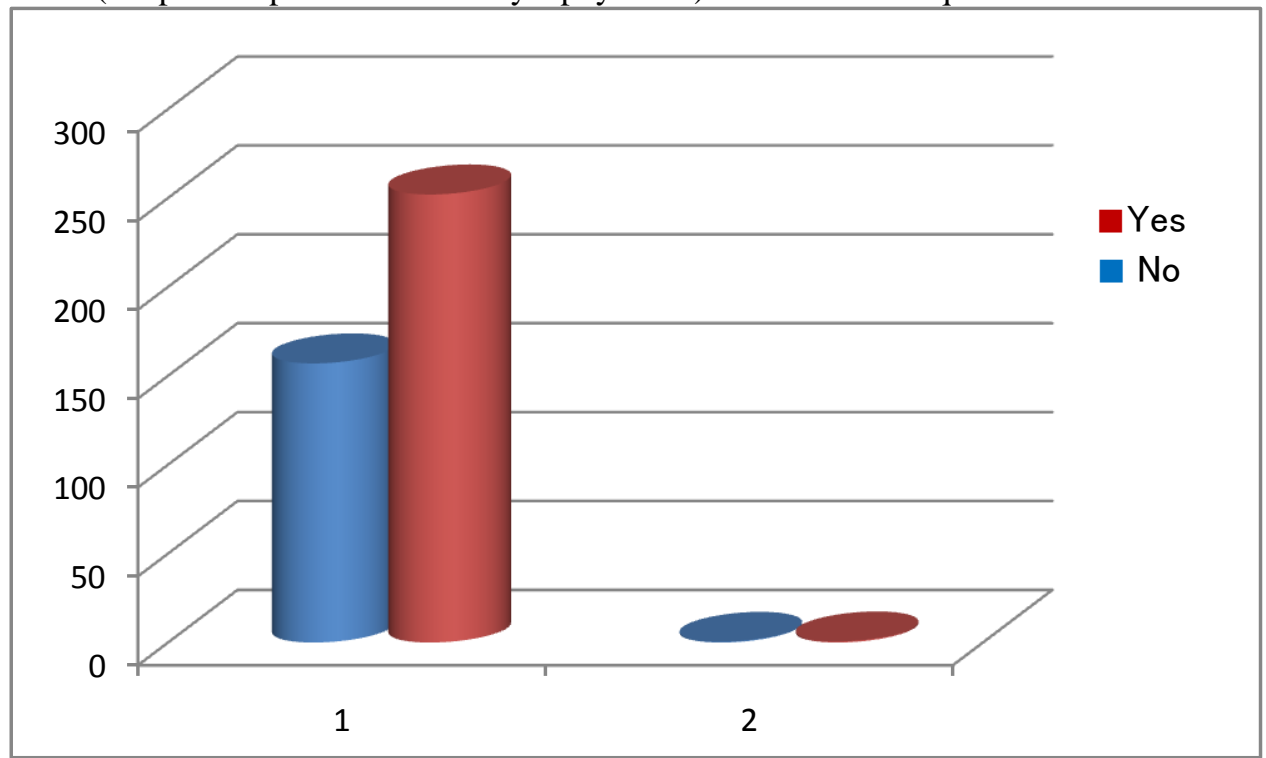

Presentation and discussion of the results of the seventh question on "Do you heard before about the bacterial resistance to antibiotics?"

The frequencies and percentages of the sample individuals were calculated according to the answer of "Do you ever heard about the bacterial resistance to antibiotics?" question.

7. The distribution of sample individuals according to the answer of "Do you ever heard about the bacterial resistance to antibiotics?" question:

Table 7:- Sample individuals' distribution according to the answer of "Do you ever heard about the bacterial resistance to antibiotics?" question

\begin{tabular}{|l|l|l|l|}
\hline No. & "Do you ever heard about the bacterial resistance to antibiotics & Frequency & Percent \\
\hline 1 & No & 164 & $40.1 \%$ \\
\hline 2 & Yes & 245 & $59.9 \%$ \\
\hline & Total & 409 & $100.0 \%$ \\
\hline
\end{tabular}

As it is shown intable No.7 that a percentage of $(40.1 \%)$ of sample individuals had not heard before about the bacterial resistance to antibiotics, while there is a percentage of $(59.9 \%)$ of sample individuals had heard before about the bacterial resistance to antibiotics. These results were attributed to the increase in the medical counseling and awareness about the different types of bacteria socially or through the media which contributed to increase the sample individual's knowledge about the bacterial resistance to antibiotics. 
Chart 7:- Shows sample individuals' distribution according to the answer of "Do you ever heard about the bacterial resistance to antibiotics?" question

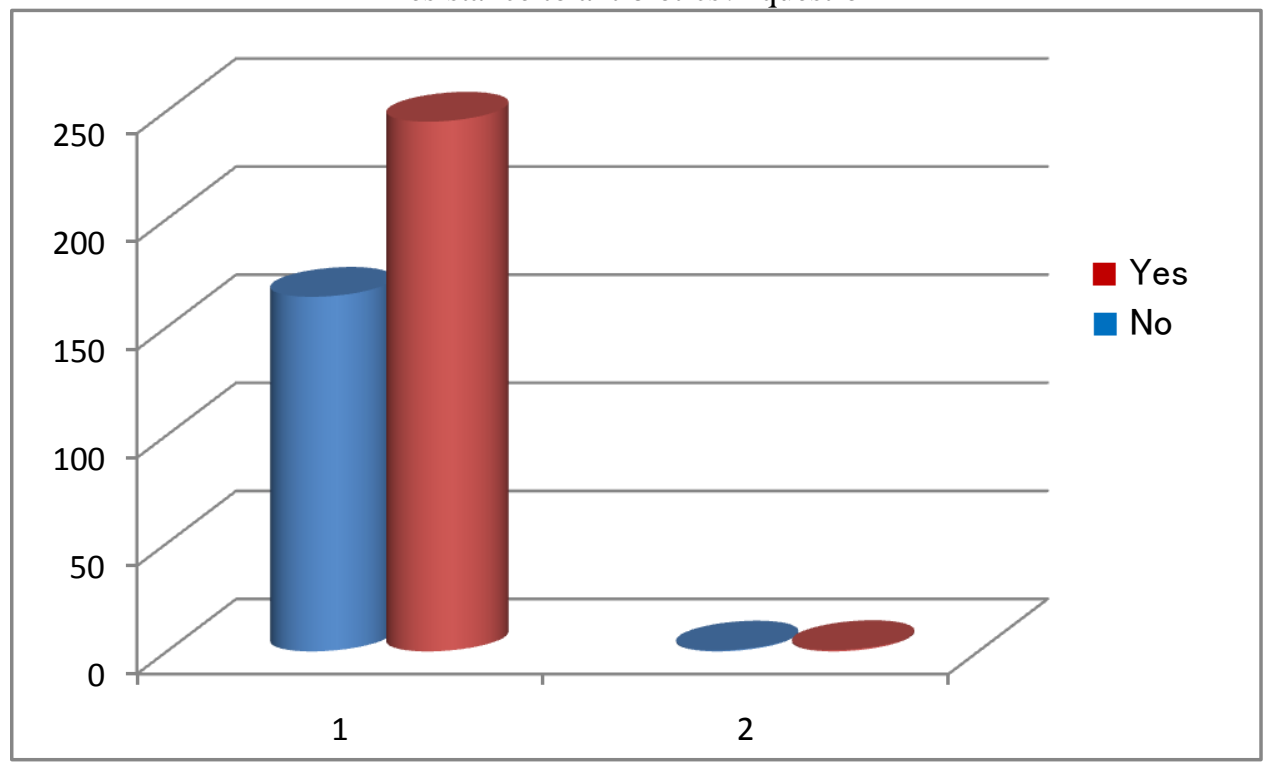

Presentation and discussion of the results of the eighth question"Do you think that the bacterial resistance to antibiotics develops in a case of an uncompleted antibiotics course?"

The frequencies and percentages of the sample individuals were calculated according to the answer of "Do you think that the bacterial resistance to antibiotics develops in a case of an uncompleted antibiotics course?" question.

8. The distribution of sample individuals according to the answer of "Do you think that the bacterial resistance to antibiotics develops in a case of an uncompleted antibiotics course?question:

Table 8:- Sample individuals' distribution according to the answer of "Do you think that the bacterial resistance to antibiotics develops in a case of an uncompleted antibiotics course?" question

\begin{tabular}{|l|l|l|l|}
\hline No. & $\begin{array}{l}\text { Do you think that the bacterial resistance to antibiotics develops in a case } \\
\text { of an uncompleted antibiotics course? }\end{array}$ & Frequency & Percent \\
\hline 1 & No & 123 & $30.1 \%$ \\
\hline 2 & Yes & 286 & $69.9 \%$ \\
\hline & Total & 409 & $100.0 \%$ \\
\hline
\end{tabular}

As it is shown intable No.8 that a percentage of $(30.1 \%)$ of sample individuals do not think that the bacterial resistance to antibiotics appears in a case of an uncompleted course of antibiotics, whilethere are a percentage of (69.9\%) of sample individuals do believe that the bacterial resistance to antibiotics appears in a case of an uncompleted antibiotic course. These results were attributed to the majority of sample individuals' conviction about the importance of completing the medical course appropriately according to doctor's instructions. Perhaps, the reason behind this is due to the increase in medical awareness among the sample individuals, which enabled them to believe in the importance of completion of a specific course of treatment. 
Chart 8:- Shows Sample individuals' distribution according to the answer of "Do you think that the bacterial resistance to antibiotics develops in a case of an uncompleted antibiotics course?" question

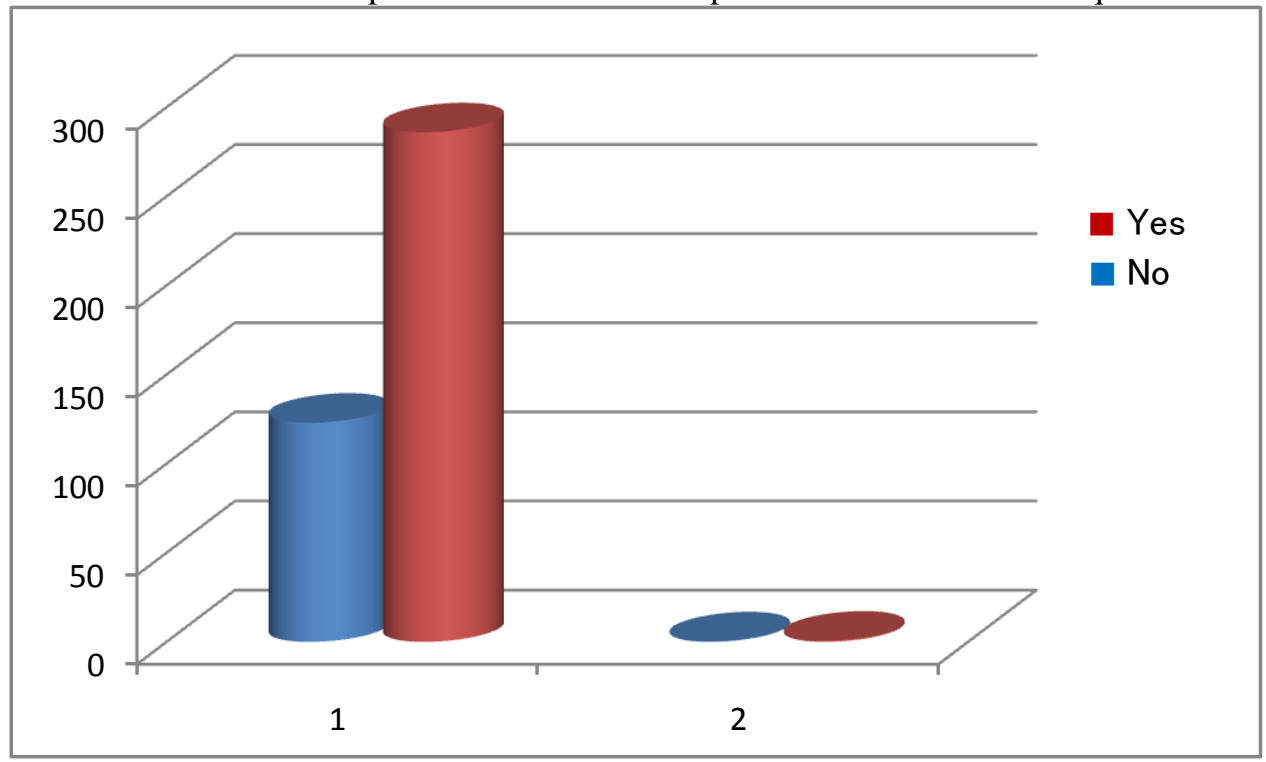

Presentation and discussion of the results of the ninth question about "Taking the antibiotic often by whom?" The frequencies and percentages of the sample individuals were calculated according to the answer of "Taking the antibiotic is often by whom?" question.

9. The distribution of sample individuals according to the answer of "Taking the antibiotic is often by whom?" question:

Table 9:- Sample individuals' distribution according to the answer of "Taking the antibiotic is often by whom?" question

\begin{tabular}{|l|l|l|l|}
\hline No. & "Taking the antibiotic is often by whom?" & Frequency & Percent \\
\hline 1 & Doctor & 243 & $59.4 \%$ \\
\hline 2 & Pharmacist & 110 & $26.9 \%$ \\
\hline 3 & Someone who take it before & 13 & $3.2 \%$ \\
\hline 4 & By yourself & 43 & $10.5 \%$ \\
\hline & Total & 409 & $100.0 \%$ \\
\hline
\end{tabular}

As it is shown intable No.9 that a percentage of $(59.4 \%)$ of sample individuals are often taking the antibiotics by doctor, while there are a percentage of (26.9\%) of sample individuals are taking antibiotics often by the pharmacist, a percentage of (3.2\%) of sample individuals are taking the antibiotics often by someone who has tried it before, and the percentage of $(10.5 \%)$ of sample individuals are taking the antibiotics often by themselves. These results were attributed to the conviction and belief of sample individuals in doctor's role which can't be replaced by anyone, even if they were people of confidence but are non-specialist. This makes them adhere to doctors' opinion before buying a particular antibiotic. 
Figure 9:- showssample individuals' distribution according to the answer of "Taking the antibiotic is often by whom?" question

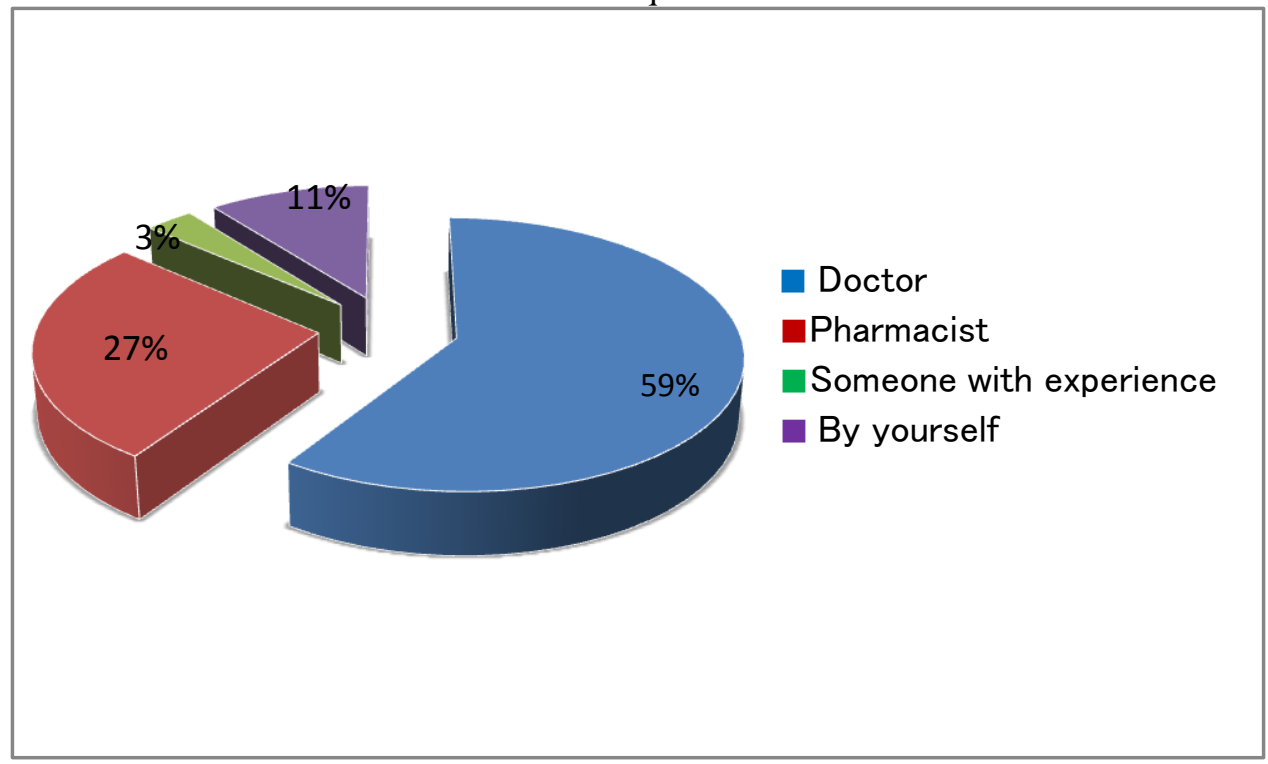

Presentation and discussion of the results of the tenth question about "What are the symptoms that drive you to buy and take antibiotics?"

The frequencies and percentages of the sample individuals were calculated according to the answer of "What are the symptoms that drive you to buy and take antibiotics?" question.

10. The distribution of sample individuals according to the answer of "What are the symptoms that drive you to buy and take antibiotics?" question:

Table 10:- Sample individuals' distribution according to the answer of "What are the symptoms that drive you to buy and take antibiotics?" question

\begin{tabular}{|l|l|l|l|}
\hline No. & What are the symptoms that drive you to buy and take antibiotics? & Frequency & Percent \\
\hline 1 & Common cold & 38 & $9.3 \%$ \\
\hline 2 & Sore throat & 251 & $61.4 \%$ \\
\hline 3 & High temperature & 107 & $26.2 \%$ \\
\hline 4 & Diarrhea & 13 & $3.2 \%$ \\
\hline & Total & 409 & $100.0 \%$ \\
\hline
\end{tabular}

As it is shown intable No.10 that a percentage of $(9.3 \%)$ of sample individuals said that common cold drives them to buy and take antibiotics, while there are a percentage of (61.4\%) of sample individuals said that sore throat drives them to buy and take antibiotics, a percentage of (26.2\%) of sample individuals said that high temperature drives them to buy and take antibiotics, and the percentage of (3.2\%) of sample individuals are derived to buy and take antibiotics by diarrhea. These results were attributed tothe fact that most of sore throat symptoms are caused by multiple types of colds and doctors often prescribe antibiotics for such a case, which is as a kind of experience of sample individuals due to the frequent exposure to common cold and their feeling of sore throat. 
Figure 10:- Shows Sample individuals' distribution according to the answer of "What are the symptoms that drive you to buy and take antibiotics?" question

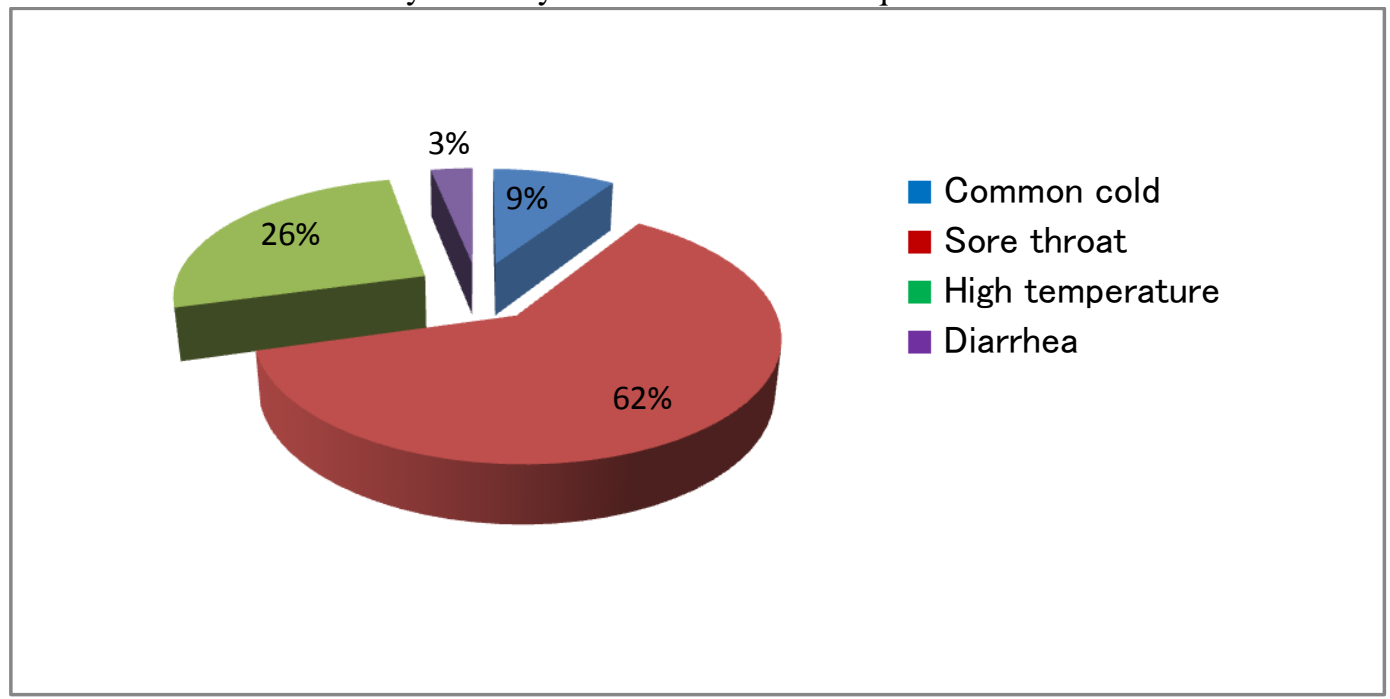

Presentation and discussion of the results of the eleventh question about "Your choice to buy antibiotic depends on what?"

The frequencies and percentages of the sample individuals were calculated according to the answer of "Your choice to buy antibiotic depends on what?" question.

11. The distribution of sample individuals according to the answer of "Your choice to buy antibiotic depends on what?" question:

Table 11:- Sample individuals' distribution according to the answer of "Your choice to buy antibiotic depends on what?" question

\begin{tabular}{|l|l|l|l|}
\hline No. & "Your choice to buy antibiotic depends on what?" & Frequency & Percent \\
\hline 1 & Price & 5 & $1.2 \%$ \\
\hline 2 & Doctor & 254 & $62.1 \%$ \\
\hline 3 & Experience or advice of someone who already used antibiotic & 50 & $12.2 \%$ \\
\hline 4 & Pharmacist & 100 & $24.4 \%$ \\
\hline & Total & 409 & $100.0 \%$ \\
\hline
\end{tabular}

As it is shown in table No.11 that a percentage of (1.2\%) of sample individuals said that their choice to buy a specific antibiotic depends on the price, while there are a percentage of $(62.1 \%)$ of sample individuals who said that their choice to buy a specific antibiotic depends on the doctor, a percentage of $(12.2 \%)$ of sample individuals said that their choice to buy a specific antibiotic depends on a particular experience or advice from someone else already used the antibiotic, and the percentage of (24.4\%) of sample individuals take their choice to buy a specific antibiotic depending on the pharmacist. These results were attributed tothe fact that most of sore throat symptoms are caused by multiple types of colds and doctors often prescribe antibiotics for such a case, which is as a kind of experience of sample individuals due to the frequent exposure to common cold and their feeling of sore throat. 
Figure 11:- shows Sample individuals' distribution according to the answer of "Your choice to buy antibiotic depends on what?" question

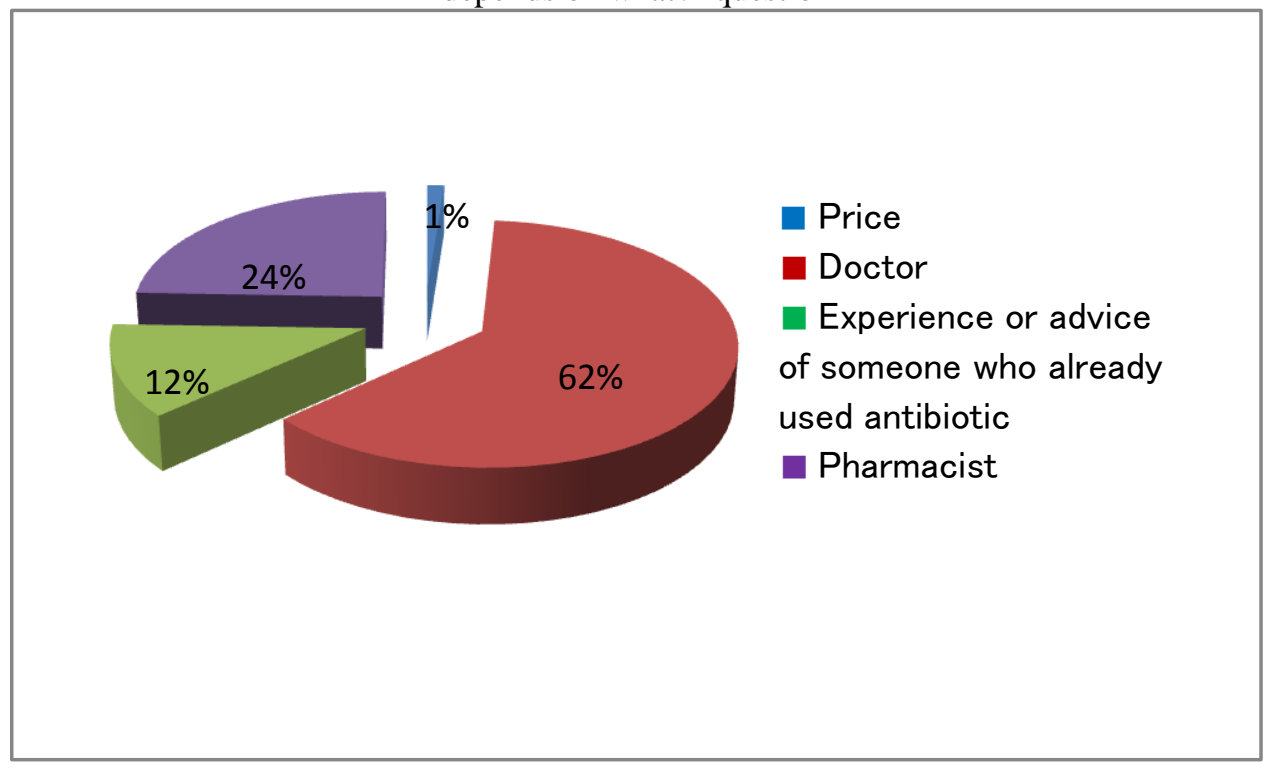

Presentation and discussion of the results of the twelfth question about "Do you see the doctor if your treatment has failed?"

The frequencies and percentages of the sample individuals were calculated according to the answer of "Do you see the doctor if your treatment has failed?" question.

12. The distribution of sample individuals according to the answer of "Do you see the doctor if your treatment has failed?"question:

Table 12:- Sample individuals' distribution according to the answer of "Do you see the doctor if your treatment has failed?" question

\begin{tabular}{|l|l|l|l|}
\hline No. & Do you see the doctor if your treatment has failed? & Frequency & Percent \\
\hline 1 & No & 96 & $23.5 \%$ \\
\hline 2 & Yes & 313 & $76.5 \%$ \\
\hline & Total & 409 & $100.0 \%$ \\
\hline
\end{tabular}

As it is shown intable No.12 that a percentage of $(23.5 \%)$ of sample individuals do not review their doctor in the case of treatment failure, while there are a percentage of $(76.5 \%)$ of sample individuals who review their doctor in the case of treatment failure. These results were attributed to the conviction of sample individuals in doctor as the worthier person who able to change the type of medication or determining another course for the treatment, which contributed to increase their review to doctor in the case of treatment failure. 
Chart 12:- Shows Sample individuals' distribution according to the answer of "Do you see the doctor if your treatment has failed?" question

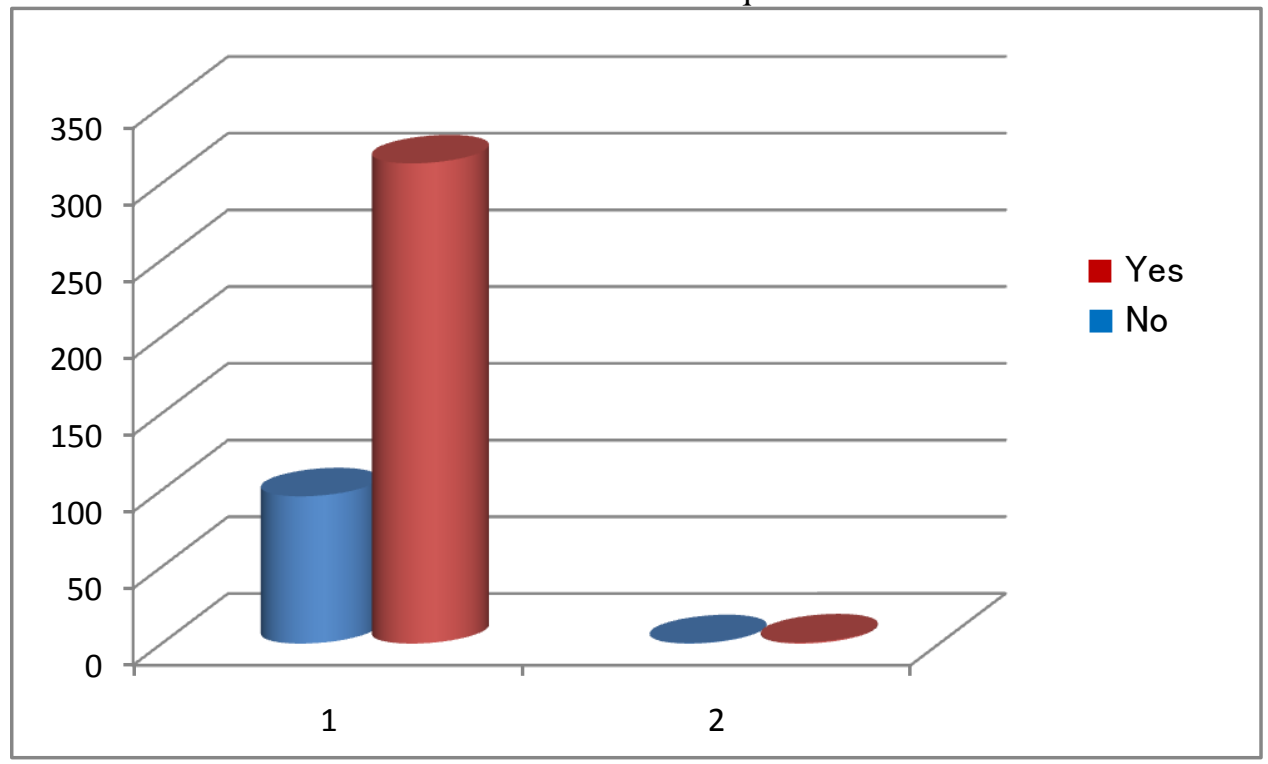

Presentation and discussion of the results of the thirteenth question about "What is the period that determines treatment failure in your opinion?"

The frequencies and percentages of the sample individuals were calculated according to the answer of "What is the period that determines treatment failure in your opinion?" question.

13. The distribution of sample individuals according to the answer of "What is the period that determines treatment failure in your opinion?" question:

Table 13:- Sample individuals' distribution according to the answer of "What is the period that determines treatment failure in your opinion?" question

\begin{tabular}{|l|l|l|l|}
\hline No. & What is the period that determines treatment failure in your opinion? & Frequency & Percent \\
\hline 1 & From one day to three days & 145 & $35.5 \%$ \\
\hline 2 & From four to six days & 122 & $29.8 \%$ \\
\hline 3 & One week & 142 & $34.7 \%$ \\
\hline & Total & 409 & $100.0 \%$ \\
\hline
\end{tabular}

As it is shown intable No.13 that a percentage of $(35.5 \%)$ of sample individuals believe that the period in which they define treatment failure in their opinion is ranging from one day to three days, whilethere are a percentage of (29.8\%) of sample individuals believe that the period in which they define treatment failure in their opinion is ranging from four to six days, and a percentage of $(34.7 \%)$ of sample individuals believe that the period in which they define treatment failure in their opinion is a week. These results indicates that there is a convergence of cognitive levels among sample individuals concerning the period to be adhered to while taking the antibiotic but it varies from one person to another, making their responses nearest to choose the period of one day to three days as they were convinced that their symptoms doesn't worth more than that as a treatment period.

Figure (13) 


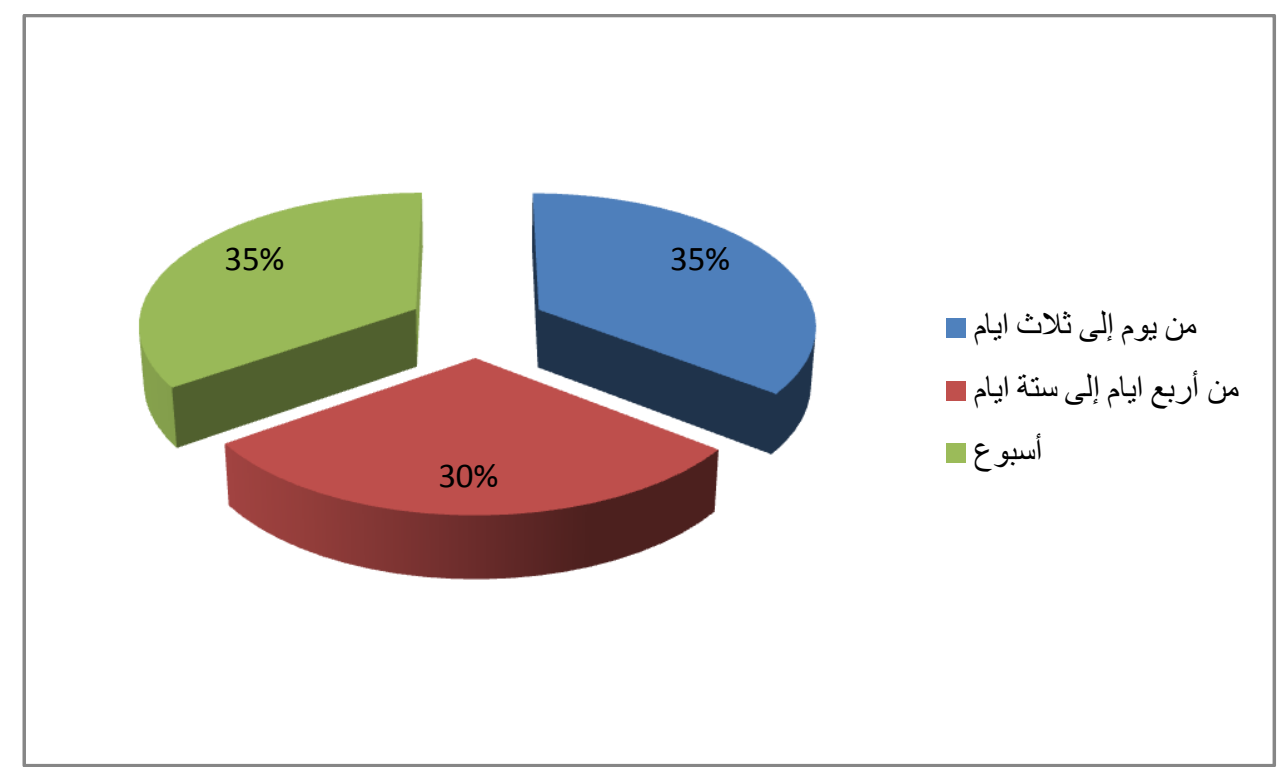

Discussions around the $14^{\text {th }}$ Question: Do you know the risks and complications of antibiotics?

The frequency and percentage of the surveyed sample have been accounted for regarding the knowledge of the risks and complications of antibiotics.

Distribution of the sample regarding their knowledge of the risks and complications of antibiotics.

Table (14)

The Distribution of the sample regarding the risks and complications of antibiotics.

\begin{tabular}{|l|l|l|l|}
\hline & Risk and Complications of Antibiotics & Repetition & Percentage \\
\hline 1 & No & 146 & $35.7 \%$ \\
\hline 2 & Yes & 263 & $64.3 \%$ \\
\hline & Total & $409-100 \%$ & \\
\hline
\end{tabular}

It is shown in Table No. (14) that the percentage (35.7\%) of respondents do not know what are the risks and complications of antibiotics, while the proportion $(64.3 \%)$ of respondents know what are the risks and complications of antibiotics, and that outcome is attributed to awareness campaigns among members the sample result, that were exposed to this type of illness or awareness efforts by the Ministry of Health in the region of Asir. 
Figure 14:- It shows the distribution of respondents according knowledge of risks and complications of antibiotics

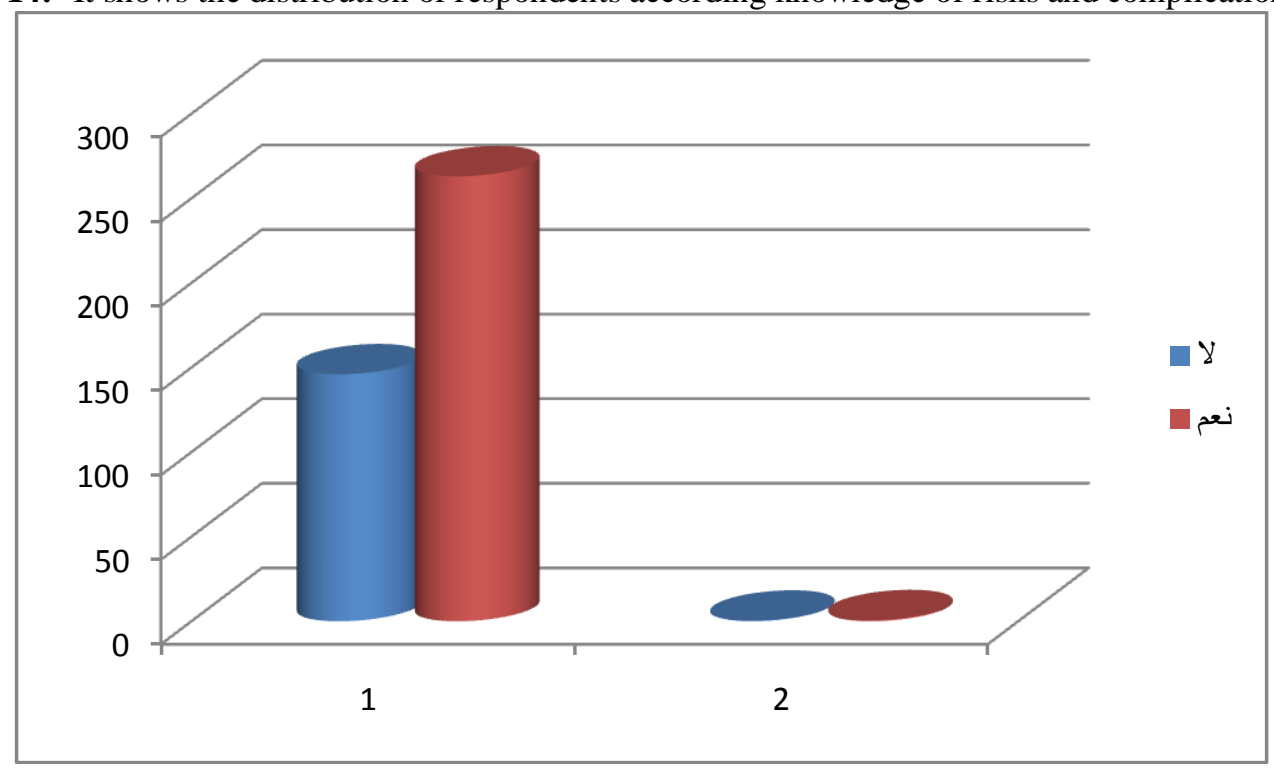

Discussions around the $15^{\text {th }}$ question: Whether or not do you know that antibiotics may interfere with other medications.

The frequency and percentage of the surveyed sample have been accounted for regarding the knowledge of interference of antibiotics with other drugs.

Distribution of the sample regarding their knowledge of interference of antibiotics with other drugs.

Table 15:- Distribution of the sample

\begin{tabular}{|c|c|c|c|}
\hline & Do You know that Antibiotics may interfere with other drugs & Frequency & Percentage \\
\hline 1 & No & 101 & $24.7 \%$ \\
\hline 2 & Yes & 308 & $75.3 \%$ \\
\hline Total & 409 & \multicolumn{2}{|c|}{$100 \%$} \\
\hline
\end{tabular}

As seen from the table (15) that the percentage (24.7\%) of respondents do not know that antibiotics may contradict with their use with certain medications, while the proportion (75.3\%) of respondents knowing that antibiotics may contradict their use with certain medications, Furthermore, aware respondents believed that each disease specific treatment and that some types of antibiotics, may interact with any type of chemical treatment/drug taken by the patient in the course of treatment of another disease and this is mainly the physician's role in raising awareness of patients. 
Figure 15:- It shows the distribution of respondents according toknowledge of risk on antibiotic interfernce with other medication.
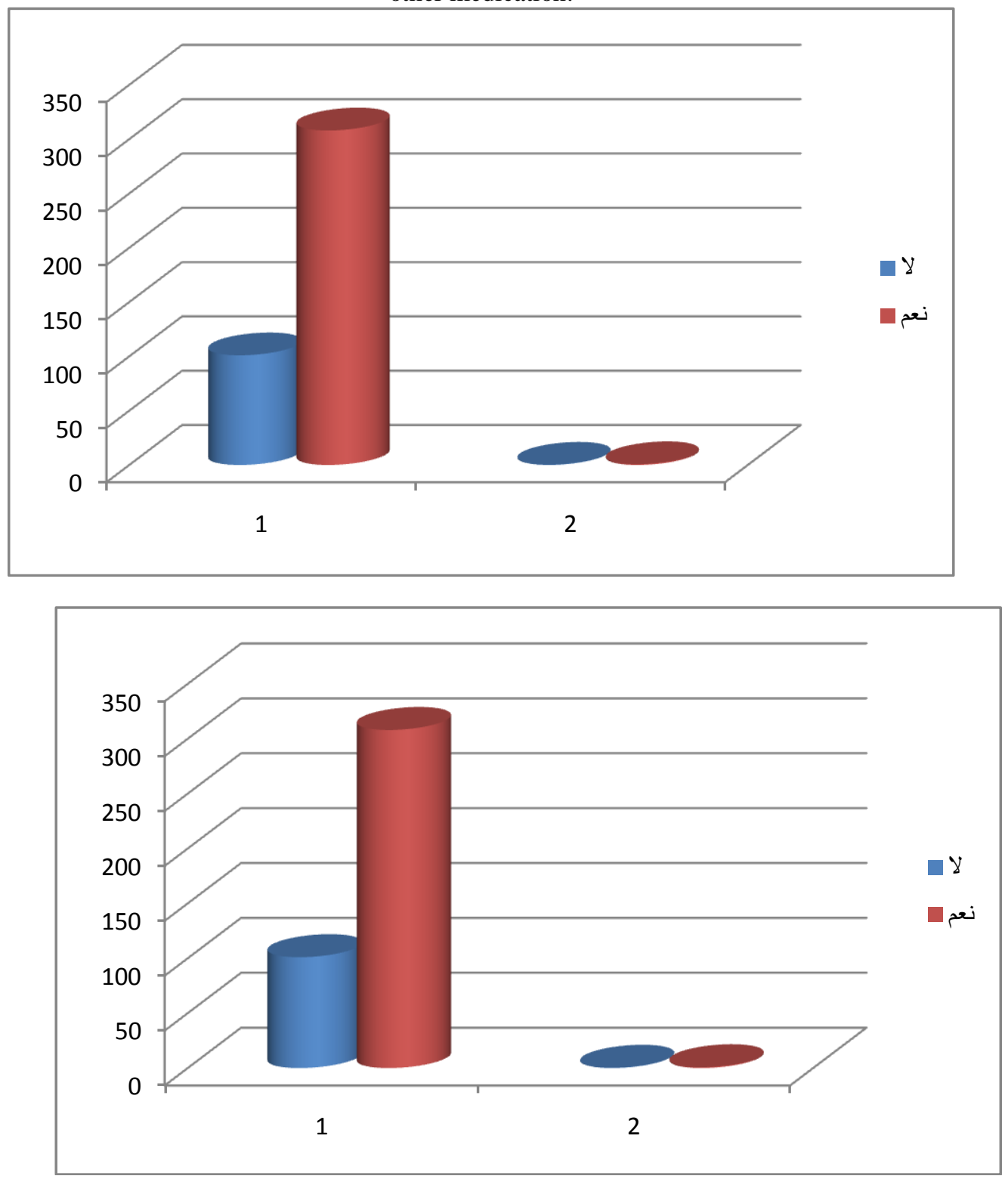

\section{Summary and Recommendations:-}

Introduction:

After the researcher presented the results of the search field results in the previous section. through the presentation of the research sample responses to questions from the research and statistically processed using descriptive statistics concepts and statistical methods, This chapter deals with the results of field research summary, and ends with providing a number of recommendations.

First: Summary of Results

Presenting the most important findings of the research according to the asked questions as follows:

- That the percentage (30.6\%) of respondents between the ages of 20 to less than 30 years.

- That the percentage $(65.8 \%)$ of the sample are female members

- That the percentage $(78.7 \%)$ of respondents hold a university degree

- That the percentage (53.3\%) of respondents do not take antibiotics without a doctor advice 
- That the percentage $(63.8 \%)$ of respondents do not consider the high temperature (Fever) a strong motivation for the use of the antibiotic.

- That the percentage (61.6\%) of the respondents usually complete the antibiotic course (the period specified for use by a physician) .

- That the percentage (59.9\%) of the respondents had heard of before by bacteria resistant to antibiotics.

- That the percentage $(69.9 \%)$ of the respondents believe that the bacteria resistant to antibiotics appear in the case of non-completion of the antibiotic course.

- That the percentage (59.4\%) of respondents are taking the antibiotic often prescribed by a doctor.

- That the percentage $(61.4 \%)$ of individuals driven by throat infections to buy antibiotics.

- That the percentage $(62.1 \%)$ of respondents said that their choice to buy a particular antibiotic depends on the doctor.

- That the percentage (76.5\%) of the respondents are head back to the doctor in the case of treatment failure.

- That the percentage $(35.5 \%)$ of respondents believe that the period in which they define treatment failure, ranges from one day to three days.

- That the percentage (64.3\%) of respondents know what are the risks and complications of antibiotics.

- That the percentage (75.3\%) of respondents know that antibiotics may interfere with some other medicines

\section{Recommendations:-}

The researchers recommendations regarding the study:

1) Sticking to the antibiotic doses and timetable to ensure maximum efficiency

2) The need for the use of the antibiotic in adherence to medical guidelines, in other words, complete a full term, even if the patient feels better

3) The need to ask the doctor, if an antibiotic is taken on an empty stomach or not and what types of food to ingested if so.

4) You should not be grinding or cracking some antibiotic pills, either because of lack stability or that the drugs have a slow release that prolongs the effect $\mathrm{f}$ the drug

5) Some antibiotics expiry date vary after solved or added to water, the expiration date is often a period of two weeks after the drug is added to water, the solution may require keeping the medicine in the refrigerator. 